\title{
Unusual Presentation of Hydatid Cyst in Cervical Region
}

\author{
1Digvijay Singh, ${ }^{2}$ Hansa Banjara, ${ }^{3}$ Varsha Mungutwar, ${ }^{4}$ Sutanu Sarkar, ${ }^{5}$ Surjit Singh
}

\begin{abstract}
Cervical involvement of the hydatid disease is rare entity occurring in less than $0.5 \%$ of patients. Hydatid disease is prevalent in Asia, Australia, and Eastern and Southern Europe. Hydatid disease caused by Echinococcus granulosus is often manifested by a slow-growing cystic mass. Hydatid cysts may be found in almost every part of the body; however, the lungs and liver are the most involved locations. This study reports an unusual presentation of the hydatid cyst over cervical region of neck.
\end{abstract}

Keywords: Cervical region, Cyst, Echinococcus, Hydatid.

How to cite this article: Singh D, Banjara H, Mungutwar V, Sarkar S, Singh S. Unusual Presentation of Hydatid Cyst in Cervical Region. Int J Head Neck Surg 2015;6(3):112-114.

\section{Source of support: Nil \\ Conflict of interest: None}

\section{INTRODUCTION}

Hydatid disease, hydatidosis, cystic Echinococcus are all terms describing infections which are caused by cestodes of genus Echinococcus usually Echinococcus granulosus. ${ }^{1,2}$ It is common in the countries of the temperate zones, including the Mediterranean countries, the Middle East, South America, New Zealand, Australia, and Southeast Asia. ${ }^{3}$ Hydatid cysts located in the head and neck region are extremely rare. Although it tends mostly to form in the liver $(75 \%)$ or lung (15\%), other organs of the body including brain, heart, bones, muscle, kidney, and pancreas may also be affected. ${ }^{4-6}$ Multiorgan involvement has been reported in 20 to $30 \%$ of hydatid disease cases. ${ }^{4}$

\section{CASE REPORT}

A 22-year-old female patient presented with complaint of slowly progressive swelling over left-side of neck of 1 year duration. There was no history of pain, fever, dysphagia, hoarseness and loss of appetite.

On examination, a diffuse swelling of size $5 \times 4 \mathrm{~cm}$ was present over left-side of neck extending vertically

\footnotetext{
${ }^{1}$ Former Senior Resident, ${ }^{2}$ Professor and Head

${ }^{3}$ Associate Professor, ${ }^{4,5}$ Former Postgraduate Student

${ }^{1-5}$ Department of Otolaryngology, Pt JNM Medical College, Raipur Chhattisgarh, India
}

Corresponding Author: Digvijay Singh, Former Senior Resident, Department of Otolaryngology, Sr. MIG-17, Sector-4 Pt Deendayal Upadhyay Nagar, Raipur, Chhattisgarh, India e-mail: drdiggi@yahoo.com from postauricular region to $4 \mathrm{~cm}$ above the left supraclavicular area under sternocleidomastoid muscle. The swelling was mobile, nontender, soft in consistency and free from underlying structure. Overlying temperature was normal. No secondary changes in skin were present. No lymph nodes were palpable. Swelling did not move on deglutition and protrusion of tongue. Rest of the ENT examinations were within normal limit.

All routine investigations were found to be normal. Ultrasonography of neck showed an intramuscular thick wall well-defined cystic mass lesion with inner hyperechoic layer of size $4.4 \times 3.6 \mathrm{~cm}$ seen at the left upper neck region suggestive of a benign intramuscular cyst or hydatid cyst. Thyroid appeared normal. Ultrasonography of whole abdomen showed an cystic mass lesion of size $2.5 \times 1.5 \mathrm{~cm}$ with inner hyperechoic layer suggestive of intrahepatic hydatid cyst. Fine-needle aspiration cytology (FNAC) from left neck was swelling suggestive of benign cystic lesion. Contrast enhanced computed tomography (CECT) of neck suggestive of hydatid cyst of size $4.5 \times$ $3.7 \mathrm{~cm}$ in posterior cervical region (Fig. 1). Chest X-ray was negative for hydatid cyst. A provisional diagnosis of hydatid cyst was made on the basis of personal history, clinical features, ultrasonography and CECT findings. A preoperative course of tablet albendazole (400 mg thrice a day) was given to the patient for 1 week.

Excision of cyst was done under general anesthesia. An oblique incision was made at the junction of upper $1 / 3$ rd and lower $2 / 3$ rd of left sternocleidomastoid muscle. The sternocleidomastoid muscle was cut and retracted for better exposure. The cyst was separated from the surrounding muscles and soft tissues with precise dissection. Particular care was given during the dissection to avoid any undue rupture and spillage of intracystic fluid. As the cyst became well-visualized, intracystic fluid was aspirated with a syringe. About 30 cc of crystal clear fluid was aspirated out. The syringe was removed keeping the needle in situ. This was followed by an intracystic injection of 3\% hypertonic saline through the same needle. The cyst was then completely separated from the remaining soft tissue attachments and removed. Macroscopic examination revealed the presence of a single cyst distinctively separated from surrounding tissue with a thin and light yellow colored wall (Fig. 2). The outer layer was reddish in color and attached to surrounding structures (Fig. 3). Postoperative period was uneventful. Histopathological 


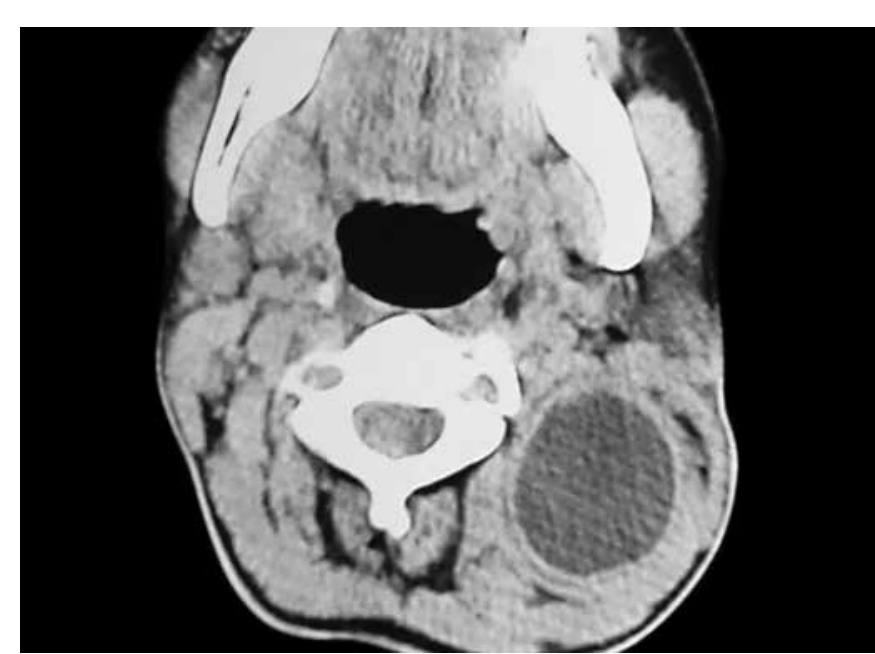

Fig. 1: Computed tomography scan of neck showing a welldefined cystic lesion on left-side suggestive of hydatid cyst

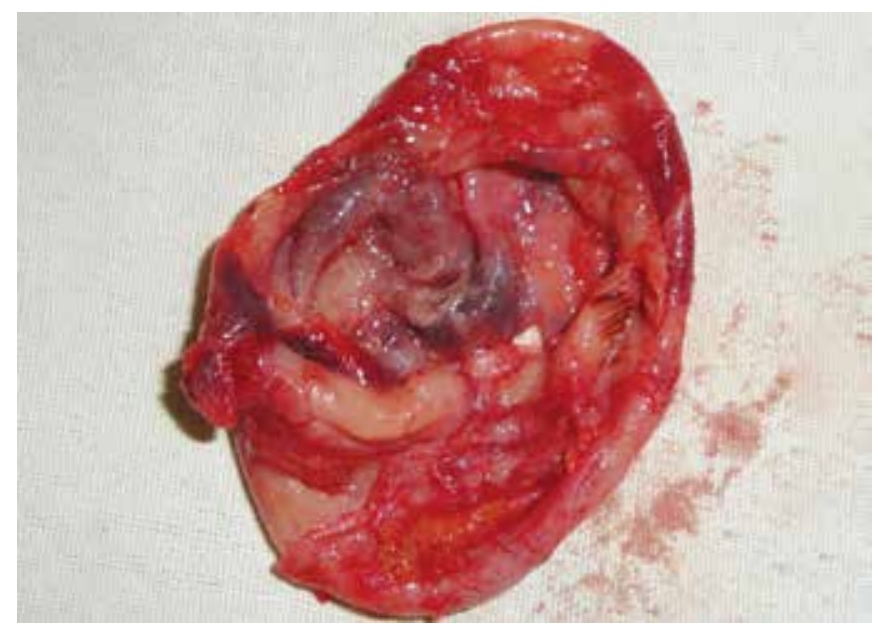

Fig. 3: Macroscopic picture of outer layer of hydatid cyst

report was consistent with hydatid cyst with a typical lamellated cyst wall and presence of protoscolex (Fig. 4). In postoperative care tablet albendazole $400 \mathrm{mg}$ thrice a day for 21 days was started along with other medications. On 8 months of follow-up, no recurrence was noted.

\section{DISCUSSION}

Hydatid disease is a parasitic infestation caused by the Echinococcus granulosus. Although most cysts are caught in the hepatic sinusoids, which are carried out by the portal vein, making the liver the most frequently involved organ, a few ova may pass through the liver, heart, and pulmonary capillaries and reach the general circulation to lodge in such sites, e.g. orbit, bones, and other internal organs. ${ }^{7}$ The disease is most frequent in sheep raising Mediterranean region. Hydatid cysts located in the head and neck region are extremely rare, even in geographic areas in which echinococcal infestation is frequent. ${ }^{8}$

The life cycle of Echinococcus involves definitive and intermediate host. Echinococcus granulosus a small (3-5 mm

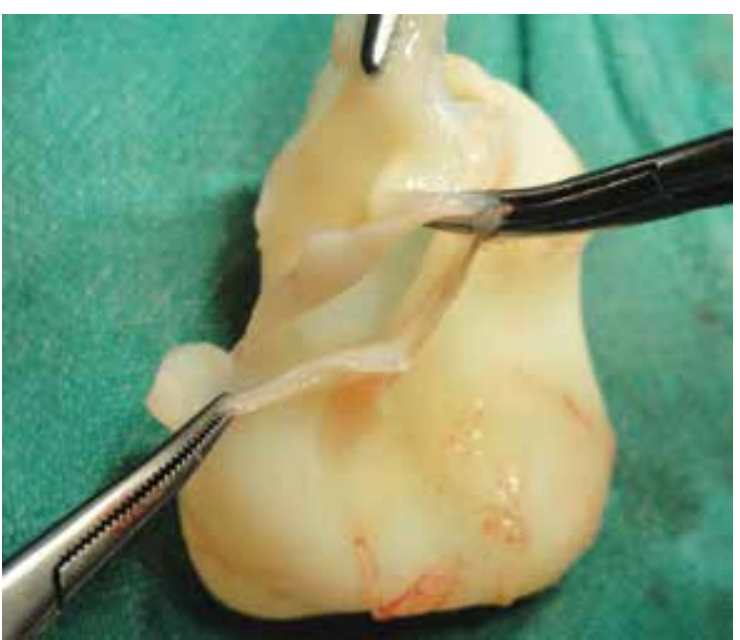

Fig. 2: Macroscopic picture of thin and light yellow colored inner wall of hydatid cyst

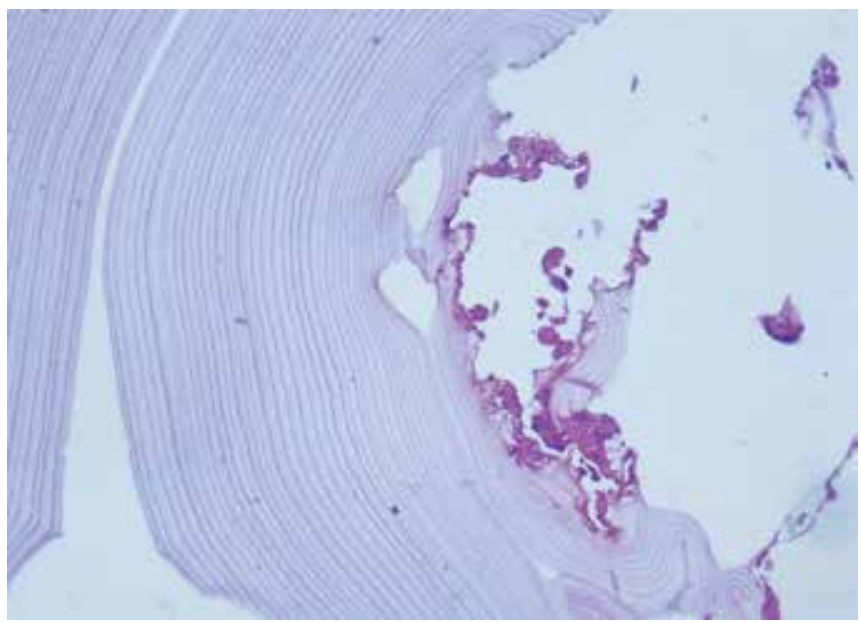

Fig. 4: Histopathological picture showing a typical lamellated cyst wall and proctoscolex suggestive of hydatid lesion

long) tapeworm that resides in the jejunum of dog (definitive host) and other canines and produces eggs that are trapped in stool. The life cycle begins when worms in the intestine of dog produces eggs, which are then expelled in feces and are released to environment. These are infective to intermediate host like sheep and accidentally humans. After ingestion of eggs by the intermediate hosts through the ingestion of contaminated fruits or vegetables, digestive enzyme liberates an embryo in duodenum that passes through intestinal mucosa to portal circulation and migrates to visceral organs. As liver filters out most of larvae, most cysts occur in liver. ${ }^{9}$

A hydatid cyst will typically have a trilaminar wall. The outermost layer is called the ectocyst and is comprised of compressed host tissue. The intermediate layer is called the laminar layer; and derived from the parasite. The germinal layer, is live cellular parasite tissue which is responsible for cyst growth and production of protoscolices, brood capsules (budded off pieces of germinal layer with attached protoscolices) and daughter cysts. 
The fluid contained in an uncomplicated hydatid cyst is crystal clear and odorless. ${ }^{10}$

The clinical course depends on the site of involvement, the size, and pressure caused by the enlarged cysts. ${ }^{11}$ The growth rate of hydatid cyst ranges from 1 to $5 \mathrm{~cm}$ per year. ${ }^{12}$ In our case, it was also a slow growing cystic lesion of 1 year duration.

In our case, the FNAC result was reported as benign and cystic lesion. The FNAC has minimal complications and is efficient for diagnosis of hydatid cysts of soft tissues. However, fine-needle aspiration biopsy is not advised because of potential to precipitate acute anaphylaxis and spread of daughter cysts. ${ }^{13}$

The serologic tests including direct hemagglutination, latex agglutination, immunoelectrophoresis, skin tests and enzyme-linked immunosorbent assay are widely used to confirm diagnosis, although they are associated with false-negative and false-positive results. ${ }^{11,14}$ In our case, serological test was not considered as the ultrasonography and CECT showed typical features of hydatid lesion and its location help in more accurate diagnosis. The ultrasound, CT, and MRI have recently become the most sensitive of diagnostic modalities. ${ }^{8}$

The most effective treatment for hydatid cyst is surgical removal. ${ }^{15}$ In our case, we have done surgical removal of the cervical lesion with meticulous dissection accompanied by intracystic 3\% hypertonic saline injection as a scolicidal agent. A variety of scolicidal agents are described in literature, such as 10\% savlon, betadine, $20 \%$ and $10 \%$ saline, $3 \%$ hydrogen peroxide, $95 \%$ ethyl alcohol and $0.5 \%$ silver nitrate. However, many surgeons have recommended the use of $3 \%$ saline as scolicidal agent. ${ }^{16-18}$

Preoperative and postoperative 1 month courses of albendazole and 2-week of praziquantel should be considered in order to sterilize the cyst. It decreases the chance of anaphylaxis, decreases the tension in the cyst wall and reduces the recurrence rate postoperatively. ${ }^{19}$

\section{CONCLUSION}

Hydatid cyst in neck region is the unusual site and it should be considered in the differential diagnosis of swelling in the cervical region, particularly if it is of longstanding duration. An accurate diagnosis will avoid any dangerous complications, such as contamination and a fatal anaphylactic reaction.

\section{REFERENCES}

1. Wen H, New RRC, Craig PS. Diagnosis and treatment of human hydatidosis. Br J Clin Pharmac 1993;35:565-574.

2. GeorgopoulosS,KorresS, Riga M,KouvidouCH, BalatsouranD, Ferekidis E. Hydatid cyst in the duct of the submandibular gland. Int J Oral Maxillofac Surg 2007;36:177-179.

3. Akhan O, Dincer A, Gokoz A, et al. Percutaneous treatment of abdominal hydatid cysts with hypertonic saline and alcohol: an experimental study in sheep. Invest Radiol 1993;28:121-127.

4. Rauhofer U, Prager G, Hormann M, Auer H, Kaserer K, Niederle B. Cystic echinococcosis of the thyroid gland in children and adults. Thyroid 2003;13:497-502.

5. Kiresi DA, Karabacakoglu A, Odev K, Karakose S. Uncommon locations of hydatid cysts. Acta Radiol 2003;44:622-636.

6. Capoglu I, Unuvar N, Erdogan F, Yilmaz O, Caydere M. A hydatid cyst of the thyroid gland. J Int Med Res 2002;30: 206-209.

7. Eroglu A, Atabekoglu S, Kocaoglu H. Primary hydatid cyst of the neck. Eur Arch Otorhinolaryngol 1999;256:202-204.

8. Tekin M, Osma U, Yaldiz M, et al. Preauricular hydatid cyst: an unusual location for echinococcosis. Eur Arch Otorhinolaryngol 2004;261:87-89.

9. Katilmis H, Ozturkcan S, Ozdemir I, Guvenc IA, Ozturan S. Primary hydatid cyst of the neck. Am J Otol Head Neck Med Surg 2007;28:205-207.

10. Morris DL, Richards KS. Hydatid disease: Current Medical and Surgical Management. Oxford: Butterworth-Heineman Ltd; 1992. p. 3, 44.

11. Gangopadhyay K, Abuzeid MO, Kfoury H. Hydatid cyst of the pterygopalatine-infratemporal fosssa. J Laryngol Otol 1996;110:978-980.

12. Sennaroglu L, Önerci M, Turan E, et al. Infratemporal hydatid cyst-unusual location of echinococcosis. J Laryngol Otol 1994; 108:601-603.

13. Akal M, Kera M. Primary hydatid cyst of the posterior cervical triangle. J Laryngol Otol 2002;116:153-155.

14. EL Kohen A, Benjelloun A, El Quessar, A, et al. Multiple hydatid cysts of the neck, the nasopharynx and the skull base revealing cervical vertebral hydatid disease. Int J Pediatr Otorhinolaryngol 2003;67:655-662.

15. Yazdani N, Basam A, Heidarali M, et al. Infratemporal hydatid cyst: a case presenting with blindness. J Laryngol Otol 2010;124:456-459.

16. Besim H, Karayalcin K, Hamamci O, et al. Scolicidal agents in hydatid cyst surgery. HPB Surgery, 1998;10. p. 347-351.

17. Little JM, Deane SA. Hydatid disease. In surgery of the liver and biliary tract. Blumgart LH, editor. Edinburgh: Churchill Livingstone; 1988. p. 955-967.

18. Milicevic M. Hydatid disease. In Surgery of the liver and biliary tract. Blumgart LH, editor. Edinburgh: Churchill Livingstone; 1994. p. 1121-1150.

19. Goel MC, Agarwal MR, Misra A. Percutaneous drainage of renal hydatid cyst: early results and follow-up. Br J Urol 1995;75:724-728. 